\title{
INFORMATION FOR CONTRIBUTORS
}

\section{SCOPE}

Politics ANd THE Life SCIences welcomes any new original manuscript engaging politics and the life sciences simultaneously. The range of appropriate submissions is extraordinarily wide, and we especially invite work demonstrating that it is even wider than we realized.

\section{CRITERIA}

To be considered, a submission - of whatever sort, including a report of original research, a scholarly review essay, a book review, a letter to the editor, or any other item - must not have been published elsewhere, either in whole or in part or under a different title or different authorship, and it must not concurrently be under review for publication elsewhere. We will not consider a "simultaneous submission." Nor will we knowingly consider submissions whose authorship has been misrepresented, such as through "guest" authorship or ghostwriting.

A manuscript must offer new knowledge or new understanding of existing knowledge. It must be both "political" and "life-scientific" in its implications, if not in its methods. Political arguments need not be theoretical; contributions from the policy community are quite welcome. Scientific arguments may be as technical as necessary, but they must, if technical at all, remain accessible to the conscientious nonscientist.

Scholars of politics must take particular care to ensure that the life-sciences content of their submissions is well researched, well referenced, well reasoned, and well written. Scholars of the life sciences must take equal care to ensure that the political content of their work is historically accurate, philosophically aware, analytically sound, and rhetorically cautious. Some contributors do well to seek coauthors. All do well to ask colleagues in different disciplines to comment on papers prior to submission.

No submission is too short or too long to be considered, but only those that make and defend good arguments both fairly and efficiently will be accepted. No subject is too controversial for PLS, but some papers are more controversial than they need be; these will not be accepted, at least not without substantial revision. Papers must be in nearly final form when submitted; they must not be "rough drafts."

An especially important criterion is the quality of composition. Poorly composed papers will be rejected, intellectual virtues aside, if the editorial effort needed to improve them to PLS standard seems likely to be excessive. Papers written by scholars adapting to English will be given special consideration but must still be compositionally sound, at least insofar as structure.

\section{FORMAT}

Contributors might usefully examine PLS formatting conventions in a recent print issue or an article downloaded from our website. Contributors lacking personal-access or library-access downloading privileges should still be able to find a "Free PDF" online.

An abstract is required; a structured abstract often is advisable. Description of methods, where appropriate, should be sufficient to allow replication. Data and their analysis should be reported in standard ways. Initial submissions may cite references in any comprehensible fashion; final submissions must adopt the currently prescribed style.

PLS in the past employed an "author-date" referencing style but since the March 2002 issue has used a numbered style, which allows in-line citation
- such as in many, $1,2,4,8$ though not all,
$3,5,6,7$ scientific journals. In-line citation is less intrusive visually, as it minimizes textual disruption, making heavily referenced papers far easier to read than they would be in "author-date" mode.

References must be assembled, in the order cited, as endnotes, such as these:
6. Memorandum, Jay S. Bybee to Alberto R. Gonzales, Counsel to the President, and William J. Haynes, General Counsel of the Department of Defense, Subject: Application of Treaties and Laws to al Qaeda and Taliban Detainees, 22 January 2002 printed in The Torture Papers, p. 111.

7. Stephen Van Evera, The Causes of War: Power and the Roots of Conflict (Ithaca, N.Y.: Cornell University Press, 1999), pp. 191-192.

8. Van Evera, pp. 182-183.

9. President Bush's Interview with Diane Sawyer, 16 December 2003, http://www.abc.org.

10. Elias Canetti, Crowds and Power (New York Farrar, Straus and Giroux, 1984), p. 73.

11. Bradley A. Thayer, Darwin and International Relations: On the Evolutionary Origins of War and Ethnic Conflict (Lexington: The University Press of Kentucky, 2004), pp. 77-78, 243-274.

12. Title 18, Sections 1340-1340A, http://uscode house.gov/download/pls/18C113C.txt

13. Memorandum, Jay S. Bybee, Assistant Attorney General to Alberto R. Gonzales, Subject: Standards of Conduct for Interrogation under 18 U.S.C. 2340-2340A, 1 August 2002, in The Torture Papers, pp. $172-217$, at pp. $200,203$.

14. David Alan Rosenberg, "The origins of overkill: Nuclear weapons and American strategy, 1945-1960," International Security, Spring 1983, 7(4):3-71.

15. "A nation challenged: Notes found after the hijackings," New York Times, September 29, 2001.

16. "Focus special: The Atta document in full: Last words of a terrorist: 'All of their equipment and gates and technology will not prevent, nor harm, except by God's will. The believers do not fear such things. The only ones that fear it are the allies of Satan," The Observer, September 30, 2001, p. 17.

17. Gustav Niebuhr, "A nation challenged: The letter; Injunctions to pray and orders to kill," New York Times, September 29, 2001.

Notice that \#8 above is a repeat-reference; it cites new page numbers in an already cited source. A cross-reference would not suffice here because it would not offer the opportunity to list the new pages. However, a cross-reference to these same two pages might be used later; it would be linked to this endnote, \#8, and if \#8 somehow became, say, \#29, then the cross-reference would automatically become \#29 as well. Cross-references appear in main text as out-of-order superscripted numerical citations, but they do not appear among the endnotes. Endnote (and repeat-references) cite sources; cross-references cite endnotes (and repeat-references).

Some authors, fearing cross-referencing, might choose to repeat-reference the content of \#8, creating an entirely new endnote wherever needed and using it simply to restate \#8's content: "Van Evera, pp 182-183." If the book and page numbers referenced in \#7 needed repeat-referencing later on, and if that same book did not have different pages cited in any othe endnote, then the content of the repeat-reference would be, simply, "Van Evera."

Notice also that the endnote numbers displayed above are not superscripts. Word processors generally use exactly the same numerals for in-text citations and for endnote numbers, meaning that the endnote numbers in submitted papers are almost certainly going to be superscripts. No problem. The nicer appearance shown here will be achieved by a professional compositor; authors should not try to match it.

Endnotes must be auto-renumbering. All competent modern word processors offer auto-renumbering endnotes, usually somewhere in their "Insert" or "Insert > Footnote..." menus. To cite sources more than once, cross-referencing (as in "Insert $>$ Cross-reference...") is encouraged, though many authors find simple repeat-referencing less challenging than cross-referencing. Cross-references, if used, must be auto-renumbering, just like endnotes, but cross-references are created a bit differently. Endnote creation also has its annoyances, the most infamous being an inexplicable default setting - lower-case Roman numerals - in the most widely used word processor; this default setting can be reset but seems to need "re-resetting" more often than it should.

Some authors present laboriously hand-numbered endnotes and cross-references that look genuine on first inspection but do not renumber automatically when moved or when references are added or deleted in text higher up in the paper. Hand-numbered endnotes and cross-references often contain numbering errors and even when error-free are tricky to keep straight during editing prior to publication. Hand-numbering is not reliable, not robust, and not usable; authors of accepted papers will be asked to convert any and al hand-numbering into auto-renumbering before editing commences.

Some authors use footnotes or endnotes not to cite sources but to expand main-text arguments or, seemingly, to rework or repair them "off-stage," as it were. The effect is at best distracting and creates the impression, often a valid one, that an author could not quite decide whether certain additional material was important or not — or, if self-evidently important, just how to fit it in. Authors whose papers are accepted by $P L S$ must prior to editing remove each of these additions entirely, blending their contributory content, if any, into a single stream of main-text exposition. The same requirement usually applies to "side-bar" comments. Appendices, though, may in some instances be retained.

All submissions should display a cover page showing title and abstract but no author names or institutional identifiers. Clues to authorship should be avoided throughout. For example, "In an earlier series of reports, some of us ${ }^{1,3,5}$ have shown that..." should be changed to preserve the anonymity of peer review. One fix would be “...some ${ }^{1,3,5}$ have shown that..." Such a change need only be temporary, though. Self-reference may be restored to explicit form in an accepted paper prior to publication.

Line numbering, which most word processors now offer as an option, may be displayed on submission but is not required. Double-spacing is conventional but not necessary, as all papers are distributed to reviewers electronically as live text and can be respaced at will.

\section{SUBMISSION}

\section{Original scholarship.}

Articles can now be submitted through the ScholarOne platform at https://mc.manuscriptcentral.com/pls.

Files created by any Macintosh or Windows word processor are acceptable; most table and graphics formats are acceptable as well. If we are unable to open or read a submission we will simply ask that further attempts be made to create and send a usable file. Files saved in RTF ("rich text format") are ideal, since RTF facilitates typesetting. PDF files ("portable document format" files) are helpful adjuncts for submissions with layouts incorporating tables and illustrations or for submissions formatted for paper sizes other than the size to which a reviewer is accustomed.

Assuming appropriateness for $P L S$ in terms of topic, importance, and refinement, submissions will then be distributed to reviewers.

\section{Book reviews.}

Contributors writing about books - whether single books or selections of books on related topics can now submit their work through ScholarOne (https://mc.manuscriptcentral.com/pls). Publishers soliciting reviews should also send new works through ScholarOne. 


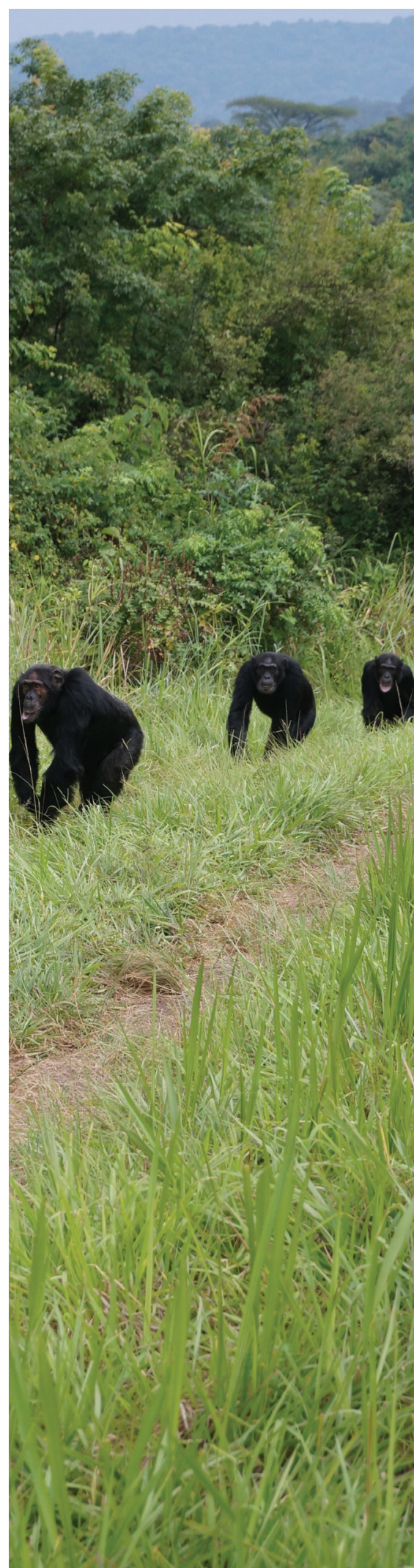

Inside this issue

\section{Politics and the Life Sciences}

VOL. 35 , NO. I

SPRING 2016

Welcome to $P L S$ ii

\section{RESEARCH ARTICLES}

The evolution of offensive realism

Survival under anarchy from the Pleistocene to the present

Dominic D. P. Johnson and Bradley A. Thayer

Shaking the tyrant's bloody robe

An evolutionary perspective on ethnoreligious violence

Jordan Kiper and Richard Sosis

Evolutionary institutionalism

New perspectives

Kai Fürstenberg

Demographic variation in how the social brain processes news messages

Irene Ingeborg van Driel, Maria Elizabeth Grabe, Ozen Bas, and Mariska Kleemans

\section{BOOK REVIEWS}

Yehezkel Dror, Avant-Garde Politician: Leaders for a New Epoch

Reviewed by Shea K. Robison

Avi Tuschman, Our Political Nature: The Evolutionary Origins of What Divides Us

Reviewed by Paul Vasholz, Jr.

Tatu Vanhanen, Global Inequality as a Consequence of Human Diversity: A New Theory Tested by Empirical Evidence

Reviewed by Charles Kroncke

(- Association for Politics and the Life Sciences, 2016
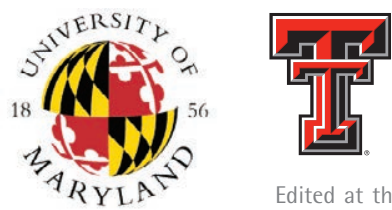

\section{TEXAS TECH}

$\mathrm{U} N$ I V E R S I T Y.

Edited at the Center for Communication Research at Texas Tech University and at the University of Maryland School of Public Policy. journals.cambridge.org/pls 